\title{
The Effect of EFL Teachers' Attitude toward English Language and English Language Proficiency on Their Sense of Efficacy
}

\author{
Farzaneh Sabokrouh $^{1}$ \\ ${ }^{1}$ Department of English Language Teaching, Science and Research Branch, Islamic Azad University, \\ Mazandaran, Iran \\ Correspondence: Farzaneh Sabokrouh, Department of English Language Teaching, Science and Research Branch, \\ Islamic Azad University, Mazandaran, Iran. E-mail: farzanehsabokrouh@yahoo.com
}

Received: August 30, 2013 Accepted: October 29, 2013 Online Published: December 5, 2013

doi:10.5539/elt.v7n1p66 URL: http://dx.doi.org/10.5539/elt.v7n1p66

\begin{abstract}
Researchers in education have documented that teachers' sense of efficacy has strong impacts on various aspects of teaching and learning. Yet, in the field of TESOL, inquiry into teachers' sense of efficacy is extremely scarce. The present study, by adopting the notion of teachers' sense of efficacy as the theoretical framework, has explored Iranian English Institute teachers' confidence in teaching English. The study has also examined teachers' attitudes toward the English language and teachers' English language proficiency, respectively. An exploratory survey methods design was employed in the present study and data were collected in the quantitative format, by which 68 English institute teachers working in Mazandaran responded to the survey. The results indicated that teachers' current level of English proficiency and EIL (English as an International Language) attitude toward the English language were the significant predictors for teachers' English teaching-specific efficacy beliefs or confidence. Also, efficacy for oral English language use was found as an additional dimension of teacher efficacy in teaching English, indicating that in a foreign language context, oral target language use would be a significant dimension to be considered in examining teachers' self-efficacy in teaching the target language.
\end{abstract}

Keywords: self-efficacy, attitudes toward English, English proficiency, Iranian EFL teachers

\section{Introduction}

Teachers' sense of efficacy has been defined as "the teacher's belief in his or her capability to organize and execute courses of action required to successfully accomplish a specific teaching task in a particular context" (Tschannen-Moran, \& Woolfolk Hoy, 2001, p. 233). It is now understood that teachers' efficacy beliefs have a profound effect on the educational process. Teachers' sense of efficacy has been linked to many positive teacher behaviors and attitudes (Tschannen-Moran \& Woolfolk Hoy, 2001), as well as student outcomes and attitudes (e.g., Henson, 2002). In addition, it has been discovered that teacher's efficacy beliefs become somewhat stable with years of experience (Tschannen-Moran \& Woolfolk Hoy, 2001), so researchers have concentrated on the development of teacher's efficacy in pre-service teachers. Some of the most influential experiences on the development of teachers' sense of efficacy are mastery experiences during student teaching.

Teachers' efficacy stems from Bandura's (1997) social cognitive theory of self-efficacy. According to Bandura, self-efficacy beliefs are an assessment of one's personal capabilities - to take action, produce results, and have control over a given situation. For example, when people with positive and negative senses of self-efficacy succeed, they both attribute that success to ability; however, when both fail, a person with a positive sense of self-efficacy attributes the failure to insufficient effort, while a person with a negative sense of self-efficacy attributes the failure to lack of ability (Gist \& Mitchell, 1992). Not all researchers agree that possession of a positive sense of teacher efficacy is necessary in order to be a successful teacher. It is possible that teachers who have doubts in their efficacy beliefs may actually be spurred to be more innovative, whereas teachers who have a very positive sense of efficacy will feel that their teaching needs no improvement.

Examining teachers' sense of efficacy or confidence in teaching English appears to be particularly pertinent and, as researchers have pointed out that teacher development is a key to its successful implementation. Teacher factor, particularly their lack of English proficiency, has been pointed out as one of the biggest obstacles for successful teaching and learning of English (Butler, 2004). In literature on the subject, it is largely assumed that 
teachers' lack of English proficiency has a causal relationship with their low confidence in teaching English.

There were some scarce studies focusing on the issue. For example Chacón (2005) and Shim (2001) showed inconsistent findings in terms of how English teachers' sense of efficacy is related to their language proficiency. While Chacón (2005) found that the Venezuelan middle school English teachers' sense of efficacy was positively related to their perceived language proficiency, Shim (2001) found the Korean middle and high school English teachers' sense of efficacy was not significantly related to their perceived language proficiency.

\subsection{Statement of Problem}

The widespread acknowledgement of English as a "global language" (Crystal, 1997) has led Iran, like other countries in the East Asian region, to the radical changes in its policies and practices concerning English education (Butler, 2004). These changes are crystallized in terms of mushrooming language institutes in different cities. In order to provide the human resources of these institutes, the educational managers recruit teachers of widely varied language proficiency and professional expertise. Most of the institutes do not provide any form of training courses - neither preservice nor inservice - to upgrade the teachers' language proficiency, cultural awareness and professional skills. However, it seems that even after years of English teaching in English language institutes, concerns surrounding teacher qualifications in English teaching are still very strong, particularly those related to teachers' lack of English language proficiency (Butler, 2004). In this context, the teachers' lack of English proficiency has been associated with their lack of confidence in teaching English and thus, ineffective teaching (Butler, 2004). For example, Nunan (2003, p. 601) stated, “... a major problem is that many English teachers simply do not have the proficiency, and therefore the confidence, to teach in English". In reaching this conclusion, he neither inquired into teachers' confidence in teaching English in their context nor cited a study examining teacher confidence and/or its relationship with language proficiency.

However, there are some studies that focus on this issue by examining some influencing variables. Shim (2001) showed inconsistent findings in terms of how English teachers' sense of efficacy is related to their language proficiency; while Chacón (2005) found that the Venezuelan middle school English teachers' sense of efficacy was positively related to their perceived language proficiency.

In addition, there may be other factors influencing teachers' sense of efficacy in teaching English, as Shim (2003) pointed out. One of the possible factors can be found in the recent work on pre- and in-service nonnative English speaking (NNES) English teachers' perceptions about the English language and themselves as English speakers.

Based on the abovementioned findings and comments on the abilities of non-native English teachers to teach English, it seems that English proficiency and teachers' attitude toward English can be predictors of their sense of efficacy. The present study is going to probe the issue and explore the possible casual relationships of proficiency and attitude to English teachers sense of efficacy.

\subsection{Significance of the Study}

By investigating the Iranian NNES teachers' sense of efficacy in teaching English in English institutes in relation to language proficiency and teachers' attitude toward English language, the current study can make several contributions to expanding the current state of knowledge in the TEFL field.

First, the study addresses the need to inquire into teachers' beliefs or confidence in their capability for teaching English by adopting the notion of teachers' efficacy. Although many educational researchers have documented the powerful impacts of teachers' sense of efficacy on various student and teacher aspects in teaching and learning, only a few studies have been done in the TEFL field (Shim, 2006).

Second, the current study examines the relationships between teachers' sense of efficacy and other factors such as their levels of English language proficiency and their attitudes toward the English language. However, previous studies have not touched these elements and the present study enjoys a more comprehensive perspective.

Last, the findings of the study provide useful information for both teacher educators and policymakers in (re)conceptualizing in-service (and pre-service) teacher education programs by suggesting possible links between different factors being examined.

\section{Review of the Literature}

\subsection{Self-Efficacy Beliefs}

Self-efficacy beliefs are conceived as the most central and pervasive mechanism of human agency in social cognitive theory. In relation to this, Bandura (2006) states: 
Among the mechanisms of human agency, none is more central or pervasive than belief of personal efficacy. This core belief is the foundation of human agency. Unless people believe they can produce desired effects by their actions, they have little incentive to act, or to persevere in the face of difficulties. Whatever other factors serve as guides and motivators, they are rooted in the core belief that one has the power to effect changes by one's actions. (p. 170)

Defining perceived self-efficacy as "beliefs in one's capabilities to organize and execute the courses of action required to produce given attainments" (Bandura, 1997), Bandura distinguishes self-efficacy from other constructs such as self-concept and self-esteem. First, he states that self-concept refers to "a composite view of oneself that is presumed to be formed through direct experience and evaluations adopted from significant others", thus it is mostly concerned with global self-images. Unlike self-concept, self-efficacy beliefs vary according to the domain of activities, the levels of difficulty, and the specific context. For example, one who has low efficacy beliefs in swimming may have high efficacy beliefs in soccer, while the global nature of self-concept construct may not do for this domain specificity.

Self-efficacy beliefs are also different from the construct of self-esteem, which refers to "whether one likes or dislikes oneself" (Bandura, 1997). Bandura (1997) states that self-efficacy beliefs are concerned with judgment of personal capability while self-esteem is concerned with judgment of self-worth. Therefore, one's judgment of his own capacity to perform a certain activity as quite low does not necessarily entail a loss of self-esteem. For example, one's judgment about his capability to swim is least likely to impact his self-esteem as an English teacher, unless he invests his self-worth in that activity. Also, self-efficacy beliefs predict "the goals people set for themselves and their performance attainments, whereas self-esteem affects neither personal goals nor performance". In summation, in Bandura's conception, self-efficacy is specific to a domain, the level of difficulty within the same domain, and the context. These aspects make self-efficacy beliefs different from other global constructs of self-concept and selfesteem.

The importance of self-efficacy beliefs in human functioning is summarized in Bandura's (1997) statement that "people's level of motivation, affective states, and actions are more based on what they believe than what is objectively true" (Bandura, 1997). As Pajares (2002) aptly points out, "how people behave can often be better predicted by the beliefs they hold about their capabilities than by what they are actually capable of accomplishing, for these self-efficacy perceptions help determine what individuals do with the knowledge and skills they have". While a mismatch between belief and reality is very common, belief often guides when one engages in a course of action (Pajares, 2002). Therefore, "people's attainments are generally better predicted by their self-efficacy beliefs than by their previous attainments, knowledge, or skills".

In terms of how self-efficacy beliefs influence human functioning, Bandura (2006) contends that they influence "people's goals and aspirations, how well they motivate themselves, and their perseverance in the face of difficulties and adversity". Also, self-efficacy beliefs "shape people's outcome expectations" and determine how opportunities and impediments are viewed". For example, a person of high efficacy may be more resilient in the face of adverse situations while a person of low efficacy may easily give up trying.

\subsection{Teachers' Sense of Efficacy}

The idea encompassing research on teacher efficacy or teachers' sense of efficacy is that 'teachers' beliefs about their own capacities as teachers somehow matter". Teacher efficacy has been defined in different terms: "the extent to which the teacher believes he or she has the capacity to affect student performance" (Tschannen-Moran, et al., 1998), "teachers' belief or conviction that they can influence how well students learn, even those who may be difficult or unmotivated" (Tschannen-Moran, et al., 1998), or "the teacher's belief in his or her capability to organize and execute courses of action required to successfully accomplish a specific teaching task in a particular context" (Tschannen-Moran, \& Woolfolk Hoy, 2001).

These conceptions of teachers' sense of efficacy draw on social cognitive theory, which is well captured in the following statement by Henson (2001):

Teacher efficacy as a construct has primarily stemmed from Bandura's (1997, p. 822) social cognitive theory ... , which suggests that one's efficacy beliefs are impacted by two important components: human agency and triadic reciprocal causation. ... The interplay between these symbiotic influences results in actual behavior and thought in the individual. In this model, social context, perception, and behavioral action all impact a teacher's judgment about whether she or he will be able to execute the actions necessary to positively impact student learning (self-efficacy). 


\subsection{Previous Studies Done in This Area}

Along with the growth of teacher efficacy research, teacher's sense of efficacy has been investigated in different contexts and subject matters. Researchers in the science education field, in particular, have been actively inquiring into teacher efficacy. However, in the TESL/TEFL field, research on teachers' sense of efficacy is extremely scarce (Chacón, 2002; Shim, 2001). A library search for this subject yielded only two unpublished doctoral dissertations (Chacón, 2002; Shim, 2001), one international journal article (Chacón, 2005), and two Korean domestic journal articles (Shim, 2003, 2006). All of the studies were conducted in the English as a foreign language (EFL) setting, where English is not used for daily communication purposes.

Shim (2001) found his participants had the same dimensions of efficacy as theAmerican teachers identified in Gibson and Dembo (1984, p. 98). The dimensions werePersonal Teaching Efficacy (PTE), referring to the "belief that one has the skills andabilities to bring about student learning", and General Teaching Efficacy (GTE), referring to the "belief that any teacher's ability to bring out change is significantlylimited by factors external to the teacher".

Unlike Shim (2001), Chacón $(2002,2005)$ found that the teachers' sense of efficacy was positively correlated with every area of language skills. "Substantial positive correlations" were found between PTE and perceived language proficiency.

Shim (2003) reported that "the canonical correlation analysis revealed that language proficiency variables ... accounted some variance [20\%] in teacher efficacy beliefs". While acknowledging the influence of language proficiency on teachers' sense of efficacy, he also cautioned that the finding indicates there would be other factors related to teachers' sense of efficacy.

Shim (2006) attempted to identify the dimensions of teacher efficacy beliefs specific to nonnative Korean secondary school teachers of English. Out of the total population of in-service secondary school English teachers who were working in six cities in one province, 130 were randomly selected for participation, and 118 teachers actually responded to the mailed questionnaire. Principal component factor analysis and confirmatory factor analysis identified four dimensions, including Teaching Improvement, Classroom Management, Confidence in English, and Students' Affect.

There are some studies that focus on this issue by examining some influencing variables. Shim (2001) showed inconsistent findings in terms of how English teachers' sense of efficacy is related to their language proficiency; while Chacón (2005) found that the Venezuelan middle school English teachers' sense of efficacy was positively related to their perceived language proficiency.

In addition, there may be other factors influencing teachers' sense of efficacy in teaching English, as Shim (2003) pointed out. One of the possible factors can be found in the recent work on pre- and in-service nonnative English speaking (NNES) English teachers' perceptions about the English language and themselves as English speakers.

Based on the abovementioned findings and comments on the abilities of non-native English teachers to teach English, it seems that English proficiency and teachers' attitude toward English can be predictors of their sense of efficacy. The present study is going to probe the issue and explore the possible casual relationships of proficiency and attitude to English teachers' sense of efficacy through the following research questions:

1) Is there any relationship between Iranian EFL teachers' attitude toward the English language and their self efficacy?

2) Is there any relationship between Iranian EFL teachers' level of proficiency in the English language and their self efficacy?

3) Is there any relationship among the teachers' sense of efficacy in teaching English, their attitudes toward the English language, and their level of English proficiency?

\section{Methodology}

\subsection{Participants}

The statistical population consists of all non-native EFL teachers practicing at private English institutes of Mazandaran Province at various levels either part-time or full-time. The sample was selected randomly and consisted of about 68 teachers of different sex, age and educational background. Since, there was no clue in the literature on the direct effects of the variables such as teachers' sex, age and educational background - that is their field of study at their university - these variables were not considered as moderator variables in this study and no controlling procedure was administered. 


\subsection{Instrumentation}

This study was of survey type in terms of its data collection procedure and the following tools were implemented in this study:

Proficiency Test:The proficiency test applied in this study was a revised version of a battery of a TOEFL test - a PBT version. The revision included omission of listening comprehension section and writing section for the sake of administrative considerations. However, the remaining sections, that is, tests of structure and reading comprehension, included 90 items (40 items for grammar and 50 items for reading comprehension). In order to guarantee the reliability of the proficiency test, it was piloted and the reliability index was calculated through KR-21 formula. It was found to be .78 .

Self-efficacy Questionnaire: This section was designed to measure the teachers' sense of efficacy (or confidence) in teaching English. For this, the 18-item version of the Teacher's Sense of Efficacy Scale (TSES) by Tschannen-Moran and Woolfolk Hoy (2001) was used. The reliability of the original TSES was .90 with all of the 18 items (.86 with the instructional strategies items, .86 with the classroom management items, and .81 with the student engagement items) (Tschannen-Moran \& Woolfolk Hoy, 2001).

Teachers' attitudes toward English language Questionnaire:This part of the questionnaire sought information about the teachers' attitudes toward the English language. It consisted of nine Likert-type items for which the participants were asked to rate the degree of agreement on a six-point scale $(1=$ Strongly Disagree, $2=$ Disagree, 3 Somewhat Disagree, $4=$ Somewhat Agree, $5=$ Agree, and $6=$ Strongly Agree). The researcher adapted the items from earlier studies (e.g., Matsuda, 2000, 2003, Sifakis and Sougari, 2005) on English learners' and teachers' attitudes in the "Expanding Circle" (Kachru, 1992) toward the English language.

\section{Results and Discussion}

The gathered data through three different instruments were first tabulated and then further analyzed statistically using SPSS version 16.0 software. Besides, descriptive analysis and inferential analysis were incorporated according to the proposed research questions.

In order to determine the type of analysis in terms of parametric or nonparametric statistical procedures tests of normality - Kolmogrov-Smirnov and Shapiro-Wilkes - were run the results of which is shown in table 1.

Since the study has three interval variables the following null hypotheses are formed to test the normality of the distributions of the data related to each variable:

1) The sample data related to teachers' self-efficacy are not significantly different than a normal population.

2) The sample data related to teachers' attitudes toward English are not significantly different than a normal population.

3) The sample data related to teachers' level of proficiency are not significantly different than a normal population

According to the table, the statistics of the first variable, teachers' level of self-efficacy, are .117 and .968 for Kolmogrov-Smirnov test and Shapiro-Wilkes test respectively. Both of them are not significant since the observed significance levels (.053 and .076 respectively) are above .05 . Hence, the null hypothesis is accepted and the distribution of the data is normal.

The same is true about the second variable, teachers' attitudes toward English. The observed values for Kolmogrov-Smirnov test and Shapiro-Wilkes test are .122 and .964 respectively. The observed significance value for these two tests are .053 and .058 respectively which are both above the acceptable level $\mathrm{p}<.05$. Hence, the null hypothesis is accepted and the distribution of the data is normal.

Regarding the third variable, teachers' level of proficiency, the null hypothesis is accepted because the observed values for Kolmogrov-Smirnov test and Shapiro-Wilkes test are .154 and .943 respectively. The observed significance value for these two tests are .60 and .84 respectively which are both above the acceptable level $\mathrm{p}<.05$. Hence, the null hypothesis is accepted and the distribution of the data is normal. 
Table 1 . The results of normality test

\begin{tabular}{lllllll}
\hline & \multicolumn{7}{c}{ Kolmogorov-Smirnov } \\
\cline { 2 - 7 } & Statistic & df & Sig. & Statistic & df & Sig. \\
\hline Teachers' Level Of Proficiency & .154 & 68 & .060 & .943 & 68 & .084 \\
Teachers' Level Of Self Efficacy & .117 & 68 & .053 & .968 & 68 & .076 \\
Teachers' Attitude Toward English Langauge & .122 & 68 & .053 & .964 & 68 & .058 \\
\hline
\end{tabular}

a. Lilliefors Significance Correction

Since the distributions of the data related to the variables of the study are normal the researcher applied parametric tests to analyze the data. Correlation analysis was used for the first and second research question and regression analysis was applied to the data related to the third research question.

\section{Q1: Is there any relationship between teachers'attitude toward the English language and their self efficacy?}

In order to answer this research question a null hypothesis was formed stating that there is no relationship between teachers' attitudes toward English language and their self efficacy. In order to test this hypothesis two-tailed Pearson's correlation analysis was run. The result is shown in table 2.

Table 2. The correlation between teacher's efficacy and their attitudes

\begin{tabular}{llll}
\hline Variables & Number & Correlation coefficient & (Sig.) \\
\hline Teachers' efficacy and their attitudes & 68 & .157 & .042 \\
\hline
\end{tabular}

As it is shown in the table above, the obtained correlation index and significance level are .157 and .042 respectively. The obtained significance level is less than .05 . That is, it can be concluded that the null hypothesis is rejected and there is a direct significant relationship between teachers' sense of efficacy and their attitude towards English. However, since the correlation index is not high, the relationship may not be considered as a strong one.

Q2: Is there any relationship between teachers' level of proficiency in the English language and their self efficacy?

Based on this research question a null hypothesis was formulated stating that there is no relationship between teachers' level of proficiency in the English language and their self efficacy. The result is shown in table 3.

Table 3. The correlation between teachers' self-efficacy and their level of proficiency

\begin{tabular}{llll}
\hline Variables & Number & Correlation coefficient & Sig. \\
\hline Teachers' efficacy and their proficiency level & 68 & .163 & .018 \\
\hline
\end{tabular}

As it is shown in the table above, the obtained correlation index and significance level are .163 and .018 respectively. Since the obtained significance level is less than .05 , it can be concluded that the obtained coefficient is significant at $\mathrm{p}<.05$. That is, it can be concluded that the null hypothesis is rejected and there is a direct significant relationship between teachers' sense of efficacy and their level of English proficiency. However, since the correlation index is not high, the relationship may not be considered as a strong one.

Q3: Are there any relationships among the teachers' sense of efficacy in teaching English, their attitudes toward the English language, and their English proficiency?

In relation to the third question, the related null hypothesis was formulated as saying there are not any relationships among the teachers' sense of efficacy in teaching English, their attitudes toward the English language, and their English proficiency. In order to test this hypothesis a multiple regression analysis was administered. The result is shown in table 4. 
Table 4. Regression analysis of the variables

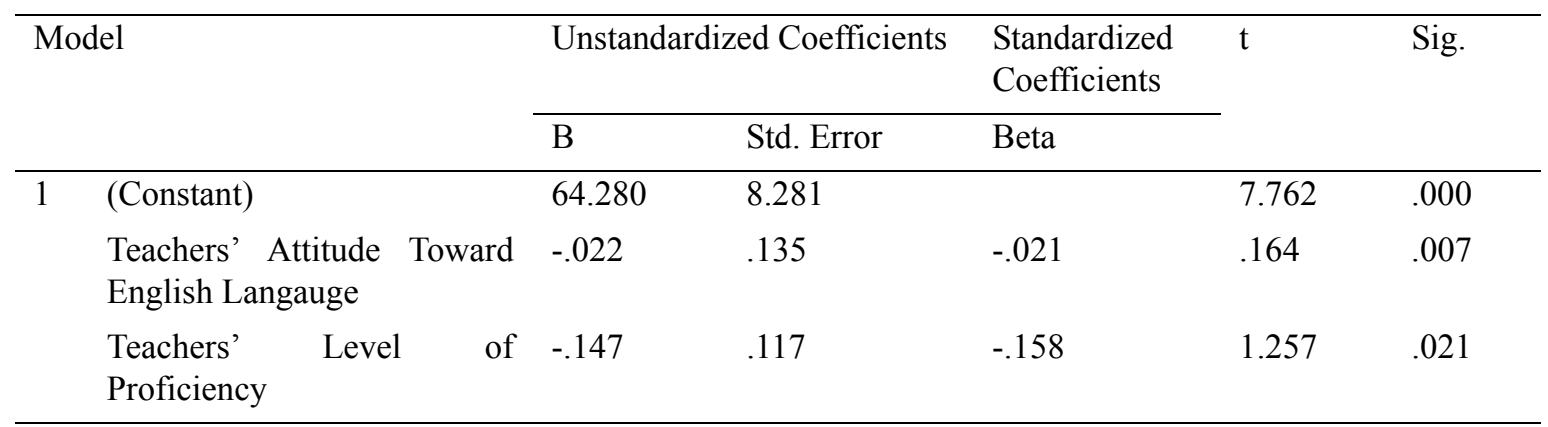

a. Dependent Variable: Teachers' Level of Self Efficacy

The table above shows that both of the variables are considered to be the predictors of the self-efficacy of the teachers. As it is shown in the table teachers' attitude gained the index of .164 and their proficiency gained the index of 1.257 in relation with the axis variable of self-efficacy with the level of significance equal to .007 and .021 respectively; that is, the indices are statistically significant at $\mathrm{p}<.05$ and $\mathrm{p}<.01$ respectively. These findings show that the null hypothesis is rejected; that is, it can be concluded that teachers' attitude to English and their level of proficiency can affect their sense of efficacy. However, as it is shown in the table, teachers' level of proficiency seems to have a stronger direct relationship with the teachers' sense of efficacy $(\mathrm{t}=1.257)$. That is, there is shown to be 98 percent certainty regarding the positive direct relationship between teachers' level of proficiency and their self-efficacy. This degree of certainty for the relationship between teachers' attitude and their efficacy is above 99 percent.

\section{Conclusion}

The present study has found that the attitude is significantly related with all of the English teaching-specific efficacy or confidence dimensions. This means the teachers who agreed more with the attitude believed they were more capable of using instructional strategies, addressing classroom management issues, engaging students in learning, and using oral English within the English class.

The significant relationship between the attitude and the teachers' English teaching-specific efficacy beliefs is in accordance with the studies that have documented the powerful link between English learners/teachers' attitudes toward English and their perceptions and confidence in themselves as English speakers/teachers.

The present study has found that English proficiency levels had a substantial relationship with all of the English teaching-specific efficacy dimensions. This result means the teachers who have higher English proficiency tended to believe more strongly in their capability for teaching English. This corroborates the previous studies that have reported significant relationships between teachers' sense of efficacy or confidence in teaching English and English language proficiency (Chacón, 2002, 2005; Shim, 2003).

As discussed earlier, the present study corroborates studies that have documented significant association between one's English language proficiency and his/her teachers' efficacy (Chacón, 2002, 2005; Kim, 2001; Shim, 2003). This suggests that improving one's English language proficiency can enhance English teaching-specific teacher efficacy or confidence. Recalling that the present study has found that the current levels of teachers' English teaching-specific sense of efficacy are moderate at best and there is a strong need to improve English proficiency among the teachers, it seems critical to provide systemic support for the teachers to improve their English proficiency.

With this in mind, however, it should also be noted that the present study has found teachers did not think that high English language proficiency was required for teaching English, though helpful if one had it. They have pointed out there are other qualifications that can override one's high English proficiency.

The current level of English proficiency and attitudes toward the English language were found to be significant predictors of the English teaching-specific teacher efficacy beliefs.

This finding of current English proficiency as a significant predictor has corroborated Chacón's (2002) study in which current speaking ability was a significant predictor of English teaching-specific personal teaching efficacy and the current reading ability of English teaching-specific general teaching efficacy. However, this finding did not corroborate Shim's (2001) study in which none of the language skills (i.e., speaking, listening, reading, and writing) were a significant predictor of Korean secondary English teachers' sense of efficacy. Even more, he 
found that "low efficacious teachers had higher speaking skills than high efficacious teachers". These findings were, as he put it, unexpected, and he called for further research examining the relationship between language proficiency and a teacher's sense of efficacy. In light of the results of the present study and Chacón's, it seems that Shim's unexpected results might have resulted from the fact that he took a non-subject specific approach in measuring teacher efficacy.

According to Bandura (1997), one's self-efficacy beliefs are highly domain-specific. Thus, when it comes to teacher's efficacy beliefs, "teachers weigh their self-perceptions of personal teaching competence in light ofthe assumed requirements of anticipated teaching task" (Tschannen-Moran and Woolfolk Hoy, et al., 2001) in their specific context. Given this, an English teacher's sense of efficacy can be best examined by asking their beliefs about their own capabilities to carry out the tasks required for them to perform in class as an English teacher. When global, non-English teaching-specific efficacy beliefs are asked, one's subject content knowledge (i.e., English language) may not matter as much as other factors like classroom management and job preparedness, as found in Shim's study.

In terms of how we can help teachers to enhance their English teaching efficacy levels, it is highly informative that the present study has found teachers' English language proficiency and attitudes toward the English language were significant predictors of efficacy for teaching English. This finding implies that teachers' confidence in English teaching can be enhanced by improving English language proficiency and promoting EIL views among teachers. With regard to the relationship between one's English language proficiency and one's confidence which has been largely assumed without empirical data in the TESOL field. Yet, as Butler (2004) points out, identifying the kinds and levels of English needed to teach English is critical because without such a common reference, one's perceived need to improve his/her English ability may not represent whether or not he/she actually needs improvement. In other words, identifying a "target language domain" (Bachman and Palmer, 1996) for teaching English can help teachers to more objectively judge their need to improve English proficiency levels, and in what types of English.

There is a need to reform in-service training programs so that they can benefit all teachers with different English proficiency levels. Offering different levels of classes can be a way to address this need, in which case a teacher who begins with a "lower" level class could reach the necessary English proficiency level by advancing to "higher" levels. However, this proposal is not likely to be adopted within the current highly centralized system of in-service training programs.

However, with centralized in-service programs (e.g., basic and advanced programs) it is hard to provide on-going training opportunities because they are intensive programs held only during summer vacation. Therefore, on-going professional development appears to be more plausible at the local level (e.g., school, local educational office). For example, the local educational offices could provide English classes of different levels for teachers on an ongoing basis, focusing on helping teachers to attain the types and levels of English they need to carry out the teaching tasks required in English classes. Teachers with lower English proficiency could begin with a "lower" level class and advance to higher level classes. In this way, they could have extended opportunities to improve their English ability. To encourage the teachers' participation in these programs, granting professional development credits to the participants could be considered.

\section{References}

Bandura, A. (1997). Self-efficacy: The exercise of control. New York: W. H. Freeman.

Butler, Y. G. (2004). What Level of English Proficiency Do Elementary School Teachers Need to Attain to Teach EFL? Case Studies from Korea, Taiwan, and Japan. TESOL Quarterly, 38(2), 245-278.

Chacón, C. T. (2002). Teachers' sense of efficacy and selected characteristics of selected English as a foreign language Venezuelan middle school teachers. (Unpublisheddoctoral dissertation, The Ohio State University, Columbus, Ohio).

Chacón, C. T. (2005). Teachers' perceived efficacy among English as a foreign language teachers in middle schools in Venezuela. Teaching and Teacher Education, 21, 257-272.

Crystal, D. (1997). English as a global language. New York: Cambridge University Press.

Gibson, S., \& Dembo, M. H. (1984). Teacher efficacy: A construct validation. Journal of Educational Psychology, 76, 569-582.

Gist, M. E., \& Mitchell, T. R. (1992). Self-efficacy: A theoretical analysis of its determinants and malleability. Academy of Management Review, 17(2), 183-211. 
Henson, R. K. (2002). From adolescent angst to adulthood: Substantive implications and measurement dilemmas in teh development of teacher efficacy research. Educational Psychologist, 37, 137-150.

Kachru, B. B. (1996). World Englishes: Agony and ecstasy. Journal of Aesthetic Education, 30(2), 135-155.

Kim, S. Y. (2001). Teachers' perceptions about teaching English through English. English Teaching, 57(1), 131-148.

Matsuda, A. (2000). Japanese attitude toward English: A case study of high school students. (Unpublished doctoral dissertation, Purdue University, Indiana).

Matsuda, A. (2003). Incorporating World Englishes in Teaching English as an International language. TESOL Quarterly, 37(4), 719-729.

Nunan, D. (2003). The impact of English as a global language on educational policies and practices in the Asia-Pacific region. TESOL Quarterly, 37(4), 589-613.

Pajares, M. F. (2002). Overview of social cognitive theory and of self-efficacy. Retrieved May 4, 2012, from http://www.emory.edu/EDUCATION/mfp/eff.html

Shim, J. W. (2001). Teacher efficacy beliefs and language skills of preservice elementary teachers of English. Yeongeoyoengmunhak [Studies on English Language and Literature], 29, 231-244.

Shim, J. W. (2003). Teacher efficacy beliefs and language skills of preservice elementary teachers of English. Studies on English Language and Literature, 29, 231-244.

Shim, J. W. (2006). Validation of dimensions of teacher efficacy beliefs specific to nonnative Korean teachers of English. Yeongeoyoengmunhak [Studies on English Language and Literature], 32, 207-224.

Sifakis, N. C., \& Sougari, A. M. (2005). Pronunciation Issues and EIL Pedagogy in the Periphery: A Survey of Greek State School Teachers' Beliefs. TESOL Quarterly, 39(3), 467-488.

Tschannen-Moran, M., \& Woolfolk Hoy, A. (2001). Teacher efficacy: Capturing an elusive concept. Teaching and Teacher Education, 17, 783-805.

Tschannen-Moran, M., Woolfolk Hoy, A., \& Hoy, W. K. (1998). Teacher efficacy: Its meaning and measure. Review of Educational Research, 68, 202-248.

\section{Copyrights}

Copyright for this article is retained by the author(s), with first publication rights granted to the journal.

This is an open-access article distributed under the terms and conditions of the Creative Commons Attribution license (http://creativecommons.org/licenses/by/3.0/). 